\title{
Cystoid macular edema associated with chemotherapy
}

\author{
Rajesh C. Rao MD, Netan Choudhry MD
}

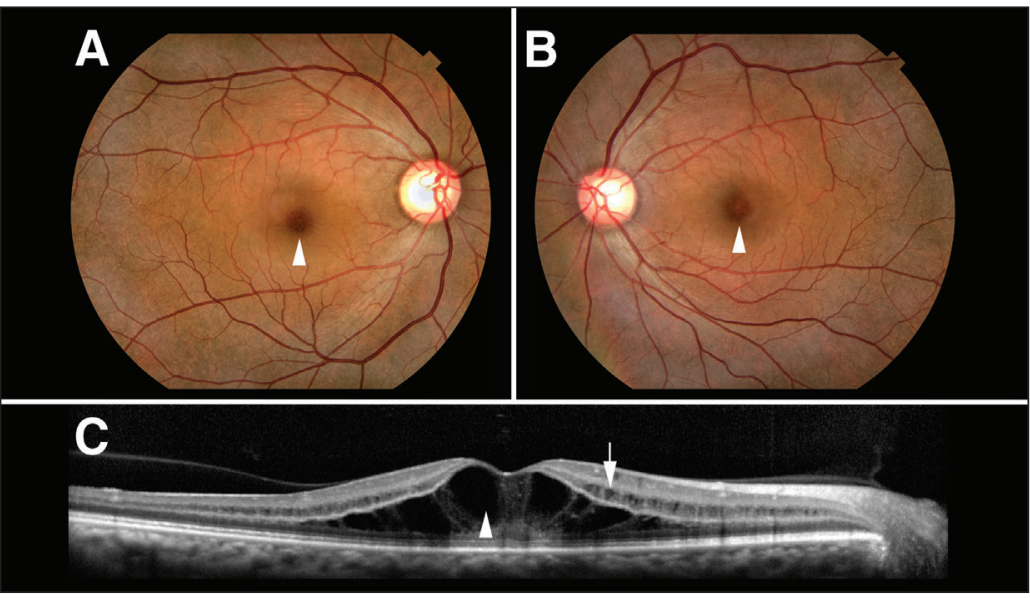

Figure 1: Funduscopic examination showing cystoid macular edema in the (A) right and (B) left eye (arrowheads) in a 45-year-old woman with recurrent breast cancer. (C) Spectral-domain optical coherence tomogram at the level of the right fovea showing intraretinal fluid in the outer plexiform layer (arrowhead) and cystoid changes in the inner retinal layer (arrow).

Competing interests: Rajesh Rao has received a grant from the US National Institutes of Health (K12EY022299). No competing interests were declared by Netan Choudhry.

This article has been peer reviewed.

The authors have obtained patient consent.

Affiliations: W.K. Kellogg Eye Center (Rao), University of Michigan Medical School, Ann Arbor, Mich.; Herzig Eye Institute (Choudhry), Toronto, Ont.

Correspondence to:

Rajesh Rao,

rajeshr@umich.edu

CMAJ 2016. DOI:10.1503 /cmaj.131080
$\mathrm{A}$ 45-year-old woman with recurrent breast sented to the ophthalmology clinic with a one-month history of decreased vision in both eyes. On examination, her visual acuity was 0.05 and her intraocular pressure was $14 \mathrm{~mm} \mathrm{Hg}$ in both eyes. Slit-lamp examination showed asymmetric optic discs and cystoid macular edema (Figure $1 \mathrm{~A}$ and $\mathrm{B}$ ). Fluorescein angiography showed only trace leakage from the retinal capillaries (Appendix 1, available at www.cmaj.ca/lookup/suppl/doi:10.1503/ cmaj.131080/-/DC1). The differential diagnosis for cystoid macular edema without substantial leakage includes nicotinic acid-associated maculopathy, $\mathrm{X}$-linked juvenile retinoschisis, various forms of retinitis pigmentosa and taxane-associated maculopathy (e.g., paclitaxel and docetaxel).

A review of the patient's medications showed that she had received weekly treatment with nanoparticle albumin-bound paclitaxel (130 $\mathrm{mg} / \mathrm{m}^{2}$ ) several months prior to this visit. She was not taking nicotinic acid, and there were no symptoms or a family history suggestive of retinitis pigmentosa. The findings in this case were consistent with taxane-associated maculopathy. After consultation with her oncologist, the patient dis- continued treatment with nanoparticle albuminbound paclitaxel, and, on follow-up examination, her vision had improved to 0.32 and 0.625 in the right and left eye, respectively. Consistent with this improvement, clinical examination confirmed a mild decrease in the cystoid macular edema, although imaging was not performed. Unfortunately, the patient died of complications associated with breast cancer after the follow-up visit.

Nanoparticle albumin-bound paclitaxel is a microtubule-stabilizing agent used to treat advanced breast, pancreatic, lung and ovarian cancers. This formulation and other taxanes, including paclitaxel and docetaxel, are linked to a serious toxic effect: reversible cystoid macular edema. ${ }^{1-4}$ Changes in vision have been reported in $13 \%$ of patients taking nanoparticle albumin-bound paclitaxel; visual disturbances were severe in only $1 \%$ of patients. ${ }^{1}$ Most toxic effects related to nanoparticle albuminbound paclitaxel have involved the anterior segment (e.g., dry eye, keratitis) and doses greater than $300-375 \mathrm{mg} / \mathrm{m}^{2} .{ }^{1}$ Previous approaches used to treat taxane-associated maculopathy have included discontinuation of the drug, topical carbonic anhydrase agents and intravitreal injection of antivascular endothelial factor antibodies. ${ }^{2-5}$ The efficacy of the pharmacologic approaches remains unknown because of the small number of patients. Clinicians caring for patients undergoing taxane-based chemotherapy should remain alert to changes in vision and consider prompt referral to an ophthalmologist, because cessation of treatment can be associated with improvement in vision.

\section{References}

1. Gradishar WJ, Tjulandin S, Davidson N, et al. Phase III trial of nanoparticle albumin-bound paclitaxel compared with polyethylated castor oil-based paclitaxel in women with breast cancer. J Clin Oncol 2005;23:7794-803.

2. Smith SV, Benz MS, Brown DM. Cystoid macular edema secondary to albumin-bound paclitaxel therapy. Arch Ophthalmol 2008; 126:1605-6.

3. Rahimy E, Sarraf D. Cystoid macular edema secondary to nanoparticle albumin-bound Paclitaxel therapy. Ophthalmic Surg Lasers Imaging Retina 2013;44:187-9.

4. Rahman HT, Yeh S, Bergstrom CS. Cystoid macular edema without leakage secondary to nab-paclitaxel (Abraxane): clinical experience with intravitreal bevacizumab. J Ocul Pharmacol Ther 2013; 29:360-2.

5. Ehlers JP, Rayess H, Steinle N. Topical dorzolamide therapy for taxane-related macular oedema. Eye (Lond) 2013;27:102-4. 